\title{
CIENCIA-FICCIÓN DIGITAL IBEROAMERICANA \\ (MUTANTES, CIBORGS Y ENTES VIRTUALES): LA RED Y LA LITERATURA ELECTRÓNICA DEL SIGLO XXI
}

\author{
POR \\ EDUARDO LEDESMA \\ University of Illinois at Urbana-Champaign
}

El ciberespacio es la última frontera a explorar para la ciencia-ficción $(\mathrm{CF}, \mathrm{o}$ ficción especulativa), más aún si las narrativas están creadas en computadoras y son desarrolladas para ser vistas/leídas en computadoras y otros soportes digitales (iPads, iPhones, espacios de realidad virtual). En relación a la ciencia-ficción digital surgen muchas preguntas: ¿Qué es la CF digital o electrónica? ¿De qué forma están los nuevos medios cambiando nuestro acercamiento a la CF? ¿Qué nuevas características podemos observar en la CF digital? ¿De qué forma se ha adaptado la CF a nuevos formatos narrativos cómo el hipertexto, los hipermedia, las blognovelas, los cómics digitales o las novelas en redes sociales? ¿Cómo logra la CF utilizar los nuevos medios para ejercer crítica cultural desde la periferia?

En este ensayo arguyo que existe una afinidad "especial" entre las nuevas formas de narrar en Internet y la CF, y que los avances tecnológicos de la informática se reflejan no sólo en el contenido sino también en la forma y la circulación de la CF digital. No se puede negar que las nuevas tecnologías están jugando un rol importante en el desarrollo cultural de Iberoamérica (incluyendo a España, Portugal y América Latina). ${ }^{1}$ Un número significativo de obras de literatura electrónica generadas en Iberoamérica se han enfocado en la CF, muchas de ellas mediante el subgénero del cyberpunk, con el propósito de explorar temas y problemáticas sociales particulares a una posmodernidad periférica. En las siguientes páginas analizaré el fenómeno de la $\mathrm{CF}$ digital iberoamericana, incluyendo su variante cyberpunk, examinando tres casos específicos: una de las primeras novelas de hipertexto, Condiciones extremas (1998) de Juan B. Gutiérrez (Colombia, 1973), un hipermedia narrativo que utiliza video y sonido, Gabriella infinita (2005) de Jaime

1 En este ensayo el enfoque está puesto en obras que son creadas en diferentes lugares pero cuya difusión en línea abarca todo el territorio hispanohablante. No es mi intención negar la gran variabilidad de acceso a Internet entre América Latina y España. En este estudio, sin embargo, me interesa explorar los elementos compartidos por muchos de los "objetos" de CF digital creados en una gran variedad de países iberoamericanos, en una lectura que parte de una posición transatlántica. 
A. Rodríguez (Colombia, 1958), y un trabajo colectivo, La huella de Cosmos (2005) coordinado por Doménico Chiappe (Perú, 1970). ${ }^{2}$

Tal como ha señalado la crítica, la CF presenta alternativas, utópicas o distópicas, al estatus quo, permitiendo al lector imaginar otros mundos posibles. En el caso de la CF digital, los mundos alternativos que se presentan están abiertos a posibilidades de interacción y participación por el lector-usuario-espectador, lo cual les proporciona una importante dimensión político-ética. Muchas de las obras iberoamericanas enfatizan lo colectivo y lo colaborativo, tanto en sus temáticas cómo en sus procesos de escrituralectura. Es más, las temáticas de estas obras incentivan la transgresión de barreras y divisiones, entre lo humano y lo pos-humano, lo orgánico y lo inorgánico, lo analógico y lo digital, y por supuesto, la ciencia y la ficción. Sobretodo, la CF electrónica de la periferia mantiene una posición (auto)crítica, paradójica y ambivalente frente a las nuevas tecnologías, consciente de sus posibilidades y peligros.

\section{¿QUÉ ES LA LITERATURA ELECTRÓNICA?}

Es preciso, antes de entrar en materia, definir la literatura electrónica y proporcionar una breve taxonomía de los formatos que adopta. La literatura electrónica, conocida también como ciberliteratura o literatura digital se define como una creación nacida de forma digital, es decir " 'digital born', a first-generation digital object created on a computer and (usually) meant to be read on a computer" (Hayles 3). Según la Electronic Literature Organization la literatura electrónica debe "work with an important literary aspect that takes advantage of the capabilities and contexts provided by the standalone or networked computer". No me refiero a textos creados en papel que han sido digitalizados, pero que no utilizan las posibilidades técnicas de la computadora como el movimiento, el sonido, o la interactividad. Tampoco me refiero a narrativas de CF escritas en papel-ya sea en libros o revistas-que tienen como referente el mundo de las nuevas tecnologías. Y es que, en este sentido, existe todo un subgénero de la CF que ha tomado al ciberespacio como eje fundamental para estructurar relatos, como en la conocidísima novela cyberpunk, Neuromancer (1984) de William Gibson. Me interesan las narrativas cyberpunk si hacen uso de los nuevos medios para crear ficciones funcionalmente "digitales", en las que el componente visual, sonoro, cinético y participativo se optimiza mediante la programación. Con la literatura electrónica nos hallamos ante un género híbrido que bascula entre lo estrictamente "literario" (palabra escrita) y el arte visual.

2 Existen otras obras importantes que se pueden clasificar como CF digital iberoamericana pero que no analizaré por falta de espacio, entre ellas Pentagonal: incluidos tú y yo (2001), de Carlos Labbé (Chile, 1977), el relato de CF y horror Hazlo (2011) de Santiago Eximeno (España, 1973), o Hearbeat (1999) de Dora García (España, 1965), o la blognovela, Detective Bonaerense (2006), de Marcelo Guerrieri (Argentina, 1973), entre otros. 
Cabe preguntar qué aporta este nuevo formato literario a la literatura, y específicamente a la CF. ¿Qué elementos formales y temáticos resultan similares o diferentes a la CF escrita en papel? ¿Cuál es, en definitiva, la afiliación especial entre el soporte digital y la materia misma de la CF?

\section{LA LITERATURA ELECTRÓNICA Y LA CIENCIA-FICCIÓN LATINOAMERICANA}

La larga tradición de la CF en América Latina se remonta al siglo diecinueve con la novela Viaje maravilloso del señor Nic-Nac al planeta Marte (1877) del argentino Eduardo Holmberg (1852-1937), obra embrionaria que ya aportaba una sátira política. En su análisis de Nic-Nac, Rachel Haywood Ferreira considera que en esa temprana etapa ya existían rasgos propios que diferenciaban a la CF iberoamericana de la anglosajona, notando que la obra utiliza los tropos del género "[...] para expresar la actitud de los argentinos hacia la ciencia y la tecnología, para explorar temas de identidad nacional y del papel de Argentina en el mundo, particularmente la dinámica de sus relaciones con Europa y los Estados Unidos" (26). Silvia Kurlat Ares demuestra que en América Latina la CF se encuentra más cercana a las ciencias sociales (soft sciences) que a las ciencias puras o aplicadas (hard sciences), estipulando que "[...] las preocupaciones capitales de la ciencia-ficción escrita en castellano y portugués rondan temáticas vinculadas con distintos aspectos de las ciencias sociales, en particular, lo sociológico, lo político, lo filosófico, (sobre todo, la epistemología) y lo psicológico, adscribiéndose a lo que se ha dado en llamar la tendencia soft de la ciencia-ficción [...]” (15).

Asimismo, la CF en América Latina ha tenido muy en cuenta la complicada situación política que ha atravesado el continente durante el siglo veinte e inicios del veintiuno, tanto en relación a las cruentas dictaduras de 1960-80, como las devastadoras secuelas económicas del neoliberalismo. Según Andrea Bell en América Latina la CF se adoptó como estrategia de resistencia indirecta:

Although science fiction writers the world over have always made use of allegory and satire to create utopias and dystopias that reflect the hidden anxieties and fears of a particular historical moment, the political realities in Latin America [...] brought about both a desire to protest injustice and a prudent need to disguise such criticism. (7)

La crítica social que diferencia a la CF latinoamericana de la anglosajona, como veremos, también está presente en los relatos digitales de la región. J. Andrew Brown y M. Elizabeth Ginway opinan que la violencia de la CF en Latinoamérica radica en la discontinua, fragmentada y agresiva historia política y social de la región:

[...] we suggest that concepts such as "fragmentation"-as seen in the use of tropes of time warps, alternate histories, and the erosion of the canon-" "divergences"-as exemplified by 
Latin America's brand of sexualized or embodied cyberpunk and apocalyptic violence distinguishing it from Anglo-American forms-and "unlikely combinations"-as found in the mix of social realism with mutants or zombies or the merging of dissonant genres such as SF, humor, and horror-prove fruitful in the study of Latin American SF. (2)

Si bien la CF en papel de los setentas y ochentas reflejaba una crítica (aunque críptica, alegórica e indirecta) contra las dictaduras, especialmente en el Cono Sur, como apuntan M. Elizabeth Ginway, J. Andrew Brown, Andrea Bell, Roberto de Sousa Causo, y otros críticos, en el periodo de los noventas hasta hoy la temática ha girado hacia una amplia gama de problemas contemporáneos como la justicia social, las relaciones entre clases, cuestiones de raza, sexualidad, religión, crimen y narcotráfico, y la degradación de las condiciones de vida en las grandes urbes, dotando las narrativas de marcas locales para establecer una especificidad cultural incluso ante las tendencias homogeneizantes que la cultura globalizada ejerce sobre las nacionales o regionales. Otros críticos como Edward King han comentado que la CF más reciente también refleja la transición de actitudes de resistencia o complicidad con las sociedades dictatoriales nacionales bajo una lógica disciplinaria en previas décadas, a las condiciones actuales en una sociedad de control consensuado y transnacional típicas del neoliberalismo en los cuales el ciberespacio se torna en la "[...] endlessly receding frontier of late capitalism" (20). ${ }^{3}$

El "salto" tecnológico de la CF iberoamericana del formato papel al digital no ha estado exento de obstáculos. Pablo Capanna juzga que los países "pobres" mantienen una relación problemática con la $\mathrm{CF}$, ya que el "atraso" tecnológico coloca al género en una situación incómoda en lo tocante a la representación de fantásticos avances demasiado alejados de la realidad diaria. ${ }^{4}$ Sin embargo, Capanna observa en El mundo de la ciencia ficción (1966) que su segundo prólogo fue escrito en 1991 en "[...] una máquina que en 1967 pertenecía a la más pura ciencia-ficción [...]” (6), refiriéndose obviamente a la computadora personal. El futuro llega, aunque desigualmente y con retraso, al Sur Global.

Ese futuro cibernético, informático, e hipertextual cuya estructura ramificada se anticipó en relatos de CF como el cuento de Jorge Luis Borges "El jardín de los senderos que se bifurcan" (1941), o en Rayuela (1963) de Julio Cortázar, obras que ya intuían múltiples caminos de lectura y lectores participativos, se ha concretado en la conjunción de la computadora personal con Internet (el uber-hipertexto). Como forma

\footnotetext{
3 La CF digital refleja también este giro temático hacia preocupaciones sociales, y las condiciones políticas actuales, al igual que se debate entre tendencias estilísticas de tipo "global", y rasgos más cercanos a la cultura local, nacional o regional. De esta forma aunque las obras están diseñadas con interés de que sean vistas y leídas más allá del ámbito nacional, no dejan de explorar temas de interés regional, e incluso hacer referencias a la historia nacional o local, y utilizan toponimias y referencias a ciudades específicas.

4 Sea como fuere, esa relación ambigua resulta productiva ya que lleva a los autores de CF iberoamericanos a cuestionar la ecuación entre tecnología/progreso y calidad de vida.
} 
literaria que ha surgido de las nuevas tecnologías, de un futuro que ya es presente, la literatura electrónica es el género que materializa la fusión entre ciencia y ficción, informática y arte. ${ }^{5}$ La CF digital es el caso particular de la literatura electrónica en el cual la temática se ajusta perfectamente a la forma: creada y ubicada en el ciberespacio, se ocupa temáticamente del rol del ser humano en relación al ciberespacio, y de las consecuencias de la fusión entre humano y máquina -el devenir de lo pos-humano-. $\mathrm{Su}$ variante iberoamericana es, en consecuencia, una reformulación de la CF digital anglosajona desde una perspectiva periférica, o sea, desde la periferia geográfica de un subgénero periférico y marginal. Sorprendentemente, a pesar de su carácter "virtual", lejos de apartarse o desterritorializarse de su conexión con Iberoamérica, la literatura electrónica ha entroncado con las preocupaciones políticas, estéticas y sociales del Sur Global. Según Jesús Martin-Barbero,

\begin{abstract}
What cyberliterature means today in Latin America is precisely the melting down (and relaunching) of the world of languages and literature, of oralities and writings, since it is taking shape in the place from which the relations between aesthetics and politics are being re-thought and re-made. An aesthetic much closer to emerging sensibilitiesnot only those of young people, but also of ethnic communities and marginalized or excluded populations or sexualities-than Art with a capital letter, and a form of politics much more interwoven with cultural rights and civic struggles than with the proletarian vanguard or electoral processes [...electronic] literature, articulates the changes which the cultural life of our countries is going through. (xii)
\end{abstract}

La literatura electrónica iberoamericana ha adoptado una óptica alineada con la CF, figurando relatos de cyberpunk, otros más cercanos a la novela negra pero marcadamente futuristas, narrativas de horror y fantasía, y ficciones sobre espacios temporalmente inciertos, pos-apocalípticos o, incluso, distópicos. ${ }^{6}$ Corroborando lo que la crítica ha observado sobre la CF latinoamericana escrita en papel, mientras los relatos anglosajones se han enfocado en futuros lejanos, la narrativa de CF escrita en línea examina futuros inmediatos y un presente apremiante e inestable, tan dinámico como aterrador. La velocidad de los cambios tecnológicos de las últimas décadas está superando las expectativas de

\footnotetext{
Hace más de dos décadas que existen publicaciones digitales de CF en español y portugués (como el e-zine argentino Axxón, creado en 1989 que, anticipándose a Internet, se repartía mediante diskettes), pero los relatos publicados en ellas son principalmente texto y no pueden considerarse literatura electrónica, stricto sensu.

6 Fredric Jameson ha establecido sugerentes conexiones entre el cyberpunk y el desarrollo del capitalismo tardío, aseverando que, "[...] when we reach late or postmodern capitalism-that stage of finance capital in which Utopian impulses and alternatives have been stifled and suppressed as much as possible-some of those energies seep into what used to be dystopian figures; and cyberpunk revels in the demonic energies of the 'sprawl' and of metropolitan excess in ways that are certainly celebratory and often protoUtopian" (161).
} 
la CF de tal modo que el presente y el futuro han colapsado en una especie de presente "futurizado", por lo cual los relatos exploran los límites extremos de tecnologías ya existentes. Por este motivo, la literatura digital se encuentra en una situación análoga al cyberpunk vis-à-vis su íntima relación con la tecnología, ya que, "The cyberpunks are perhaps the first SF generation to grow up not only within the literary tradition of science fiction but in a truly science-fictional world" (Sterling ix). ${ }^{7}$

El encuentro entre Internet y la CF ha creado nuevas posibilidades para el uso del género como herramienta artística y política, facilitando su propagación más allá de los reducidos mercados del libro en papel. El Internet ofrece las mejores posibilidades de continuación, difusión, expansión y supervivencia del género. Bell sostiene que gracias al ciberespacio se ha ampliado la capacidad participativa de los fans de CF mediante e-zines, páginas web personales y listservs dedicados al género en toda la región (12). Si bien Bell se refiere exclusivamente a la movilización de paratextos críticos y fanzines y no a la creación de relatos de CF en formato electrónico, ese paso -que ajusta el contenido a la forma- proporciona una nueva "dimensión" participativa, facilitando la inclusión del lector y la creación de obras colectivas, incentivando, en fin, un espíritu de búsqueda que es parte del espíritu imaginativo del género mismo. Los ejemplos de CF que voy a discutir a continuación utilizan el formato digital y sus posibilidades de imagen, sonido, interacción y participación del lector, potencialmente desarrollando nuevos acercamientos políticos, éticos y sociales a la CF iberoamericana.

\section{CONDICIONES EXTREMAS: ESTRUCTURAS HIPERTEXTUALES Y MUTANTES REBELDES}

Las ficciones en hipertexto son quizás la forma más "primitiva" de la literatura electrónica, remontándose a los años ochenta cuando Eastgate Systems creó la plataforma Storyspace y Michael Joyce escribió el primer hipertexto narrativo, Afternoon: A Story (1987). El hipertexto se puede definir como la unión de un grupo de textos cortos (lexias) vinculados entre sí de forma no-secuencial y asociativa, que permiten lecturas no-lineales e interactivas y facilitan la agregación de información de diferentes fuentes. El movimiento a través de un hipertexto se produce cuando el lector-usuario escoge y activa los hipervínculos (enlaces) que determinan su camino de la lectura, resultando en una experiencia única para cada lector. La lectura de ficciones hipertextuales, por lo tanto,

7 Por supuesto que la afinidad tecnológica y auto-referencial que la literatura digital comparte con el cyberpunk (Tupinipunk en Brasil) no deja de reflejar ciertas condiciones especiales en América Latina, donde problemas de adquisición de nuevas tecnologías, accesibilidad a Internet y la desigualdad económica condicionan o imposibilitan el acercamiento a la cibercultura por parte de sectores marginados. Sin embargo, el crecimiento de la conectividad aumenta, pese a la dispar distribución de tecnología que se halla concentrada aún en los barrios afluentes de las grandes ciudades. 
puede resultar algo desconcertante ya que se favorece el final abierto, la fragmentación y la indeterminación narrativa.

Condiciones extremas (1998) del matemático colombiano Juan B. Gutiérrez, es la segunda novela Latinoamericana de hipertexto (la primera, El primer vuelo de los hermanos Wright, fue escrita por el mismo autor un año antes). ${ }^{8}$ A diferencia de otros hipertextos narrativos, las obras de Gutiérrez están creadas mediante una plataforma diseñada por el autor y denominada "Literatrónica". El sistema utiliza un algoritmo de inteligencia artificial que, basándose en los enlaces que el lector va escogiendo, sugiere cuáles de los múltiples caminos posibles mantienen mayor coherencia narrativa con lo previamente leído. Asimismo, el sistema indica el porcentaje de la obra que el lector ya ha atravesado, disminuyendo de esa forma el desconcierto que provocan (a menudo intencionalmente) algunos textos digitales. En cierto modo Condiciones extremas es atípica ya que mantiene la coherencia narrativa sin sacrificar la multiplicidad de opciones de lectura. La obra permite cierta linearidad pero también saltos asociativos propiciados por enlaces e intervalos inesperados, incrementando las posibilidades dialógicas. Aunque Condiciones extremas se expresa principalmente vía texto, también posee una serie de ilustraciones estilo cómic (historieta) del dibujante colombiano Giovanni Castro, también conocido como "Nigio", que acompañan las "lexias" (ver fig. 1).

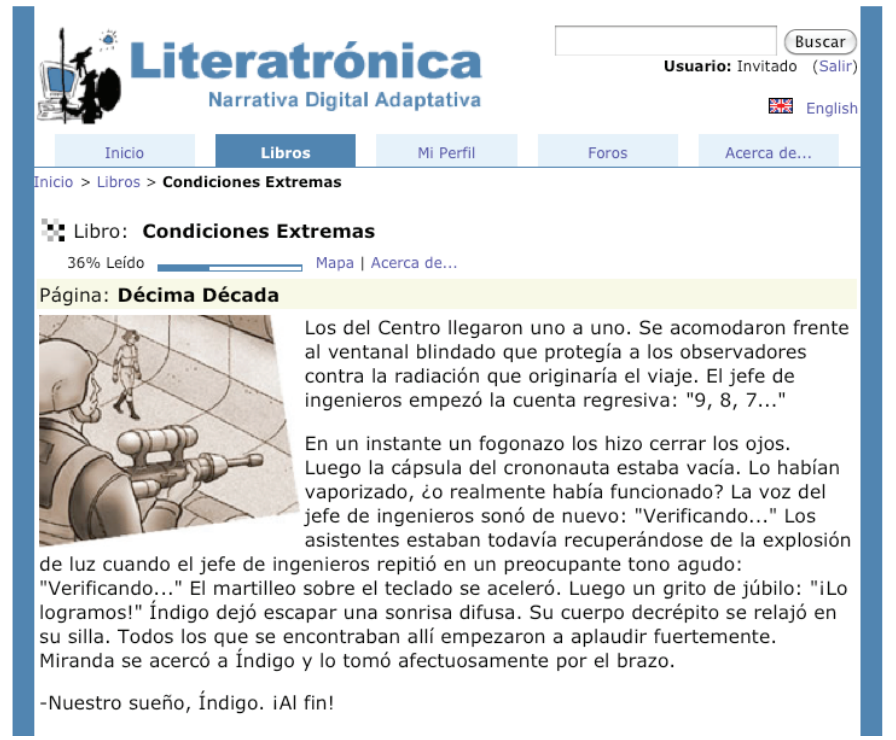

Fig. 1 Condiciones extremas (1998) - Imagen de pantalla

\footnotetext{
8 La obra fue escrita en tres versiones, 1998, 2000, y 2006. Aquí examino la última versión del 2006.
} 
La acción transcurre en la ciudad de Santa Fe de Bogotá - o suidad, el neologismo empleado para describir una ciudad posindustrial sumida en la suciedad ambiental-, recorriendo varias épocas del siglo veintiuno: la primera década, aproximadamente coetánea con el momento de escritura en 1998, la quinta -circa 2050-, la octava, y la décima, cerca del año 3000. Según el enlace escogido el lector puede "saltar" espacialmente no sólo de un punto de la historia a otro, sino de un "tiempo" a otro. Los saltos cronológicos, justificados mediante el recurso narrativo de una máquina del tiempo, sirven para contrastar una hipermodernidad que en 1998 prometía la utopía, con la situación distópica en el año 3000, que revela un planeta contaminado y sumido en un sistema de apartheid en el cual los humanos esclavizan a una raza mutante, los "avatares". Las discontinuidades temporales también desautorizan una visión teleológica de la historia, proponiendo en cambio una posmoderna retícula espacio-temporal, que, análoga a la estructura del hipertexto, permite cierta secuencialidad pero mantiene un final abierto e incierto. Con cada enlace elegido, el lector aumenta sus posibles opciones de forma arborescente, multiplicando las consecuencias de cada acto hasta (casi) el infinito, de forma que la "realidad", codificada y abierta a múltiples repeticiones, obtiene una calidad de simulacro. Tanto la "virtualización" de lo real como la "materialización" de lo virtual son temas recurrentes en el cyberpunk digital.

El paso entre diferentes lexias se corresponde con saltos temporales efectuados mediante el uso de prolepsis, analepsias, y elipsis diegéticas que dan origen a una narrativa fragmentada pero hilvanada mediante un argumento flexible en cuanto a su organización. Los "espacios" entre lexia y lexia, y las posibles discontinuidades narrativas son "completadas" por el lector mediante información adquirida en otros puntos de la narración, o mediante sus conocimientos extra textuales, de modo que el lector deviene co-creador, en el sentido barthesiano. Queda marcada, de cualquier modo, la importancia y centralidad en el ámbito del ciberespacio del concepto "información" (la manipulación de datos digitales), ya que tanto el lector como la computadora deben conseguirla, procesarla, y destilar de ella algún tipo de significado.

Los tres protagonistas de Condiciones extremas representan diversos sectores del país que compiten entre sí para alterar el catastrófico futuro mediante intervenciones en el pasado: el industrial Índigo Cavalera, la científica Miranda Macedonia y el mutante/avatar Rasid Bagda (Equinoccio Deunamor en previas versiones). Los conflictos ejemplifican el legado neoliberal: una poderosa corporación global (Industrias Cavalera) causa un desastre ecológico de dimensiones apocalípticas, volviendo el aire irrespirable excepto para una raza mutante que se ajusta a las nuevas "condiciones extremas", sólo para ser convertida por los humanos en mano de obra desechable, esclavizados, al fin, por su diferencia. La crítica social, por lo tanto, forma parte íntegra de la narración; en un momento metacrítico, Miranda, la científica "positivista" comenta: "No esperarás que durante la décima década sigamos con el mismo avance tecnológico que teníamos en la 
primera década. Ya ni siquiera somos una nación pobre", obteniendo la irónica respuesta del industrialista Índigo, "Eso no te lo creo [...] Es pura ciencia-ficción” (Gutiérrez).

En Condiciones extremas, el desarrollo de la trama demuestra que el progreso tecnológico que ha convertido a Colombia en una potencia mundial se ha logrado a costa de la destrucción del medio ambiente y de haber sumido en la pobreza a los mutantes, seres marginales e "inferiores" de su sociedad; en definitiva, la novela presenta una crítica en contra del neoliberalismo y el capitalismo tecnológico (que incluye a las nuevas tecnologías de la información), señalando la capacidad autocrítica de la CF digital latinoamericana. Indudablemente, la crítica a la desigualdad social, sea entre humanos y "avatares" o entre ricos y pobres, abunda en la novela, por ejemplo cuando el mutante Rasid confronta al capitalista, diciéndole: "Índigo, mira a tu alrededor. Llamamos desechable a un ser humano porque es mendigo y drogadicto. También éste tiene derecho a la abundancia que tú disfrutas, pero aquí lo único que abunda es la pobreza" (Gutiérrez).

Susan Pajares Tosca opina que la articulación crítica de Condiciones extremas no hubiera sido posible mediante un texto impreso, porque depende de la participación activa del lector:

Making the reader assemble the fragments herself has a purpose, it helps her realize that present, future and past are connected in many ways. [...] The hypertextual structure models the way we understand causes and consequences, playfully multiplying explanations and reasons, forcing the reader to build her own linear story in her mind. This could not be done in print, because the sense of building the story would be lost if the process had already been completed by the author. (274)

Sin embargo, según Pajares, la novela no es completamente "interactiva" ya que el lector únicamente escoge el camino a seguir sin modificar las opciones, pero sí, en cambio, proporciona una gran libertad para explorar el texto y facilita múltiples y diferentes lecturas e interpretaciones. Esa libertad de elección, aunque siga determinada por los límites y la programación de la narración, refleja las posibilidades de acción social que se abren hoy mediante intervenciones políticas en el ámbito digital. De este modo, además de exponer problemáticas sobre abuso de poder, racismo, extremismo y terrorismo, desigualdad social y los atropellos del neoliberalismo tecnologizado en América Latina, Condiciones extremas sugiere soluciones que radican en las nuevas posibilidades de participación virtual. Dichas posibilidades (por ejemplo nuevas formas de protesta y movilización a nivel local y global) pueden rebasar los límites espaciotemporales establecidos por una visión lineal y determinista de la historia, como ocurre en el relato. Sin embargo, Condiciones extremas mantiene un saludable escepticismo ante visiones ingenuamente utópicas del progreso tecno-científico, encontrando un 
balance entre tecnofilia y tecnofobia, entre la cultura global y las preocupaciones locales o regionales del contexto iberoamericano.

\section{GABRIELLA INFINITA: HIPERMEDIA COMO HIPERPUNK}

Gabriella infinita (2002), del ingeniero colombiano Jaime A. Rodríguez, es una hipermedia de CF sobre un futuro (cercano) situado en un mundo pos-apocalíptico, en el cual un personaje descubre, horrorizada, que vive, y muere, en una realidad virtual. La narrativa hipermedia es un formato que también usa hipervínculos, pero, a diferencia del hipertexto, enfatiza los elementos no textuales, activando recursos multimedia que utilizan video, sonido, y movimiento.

Claire Taylor clasifica Gabriella infinita como literatura "Macon.doc"-neologismo que alude al Macondo del realismo mágico garciamarquesino (literatura del Boom) y al "McOndo" posmoderno, urbano y tecnológico- para definir "nuevas representaciones del espacio latinoamericano que no dejan de ser míticas" (198). Asimismo, Gabriella infinita ejemplifica los estrechos vínculos temáticos que existen entre ciertas narrativas de hiperficción y el cyberpunk latinoamericano, derivando en lo que podríamos denominar "hiperpunk", o relato de cyberpunk en formato hipermedia. ' Según Taylor, "Los autores de las nuevas ficciones hipermedia," comenta Taylor, "crean mundos urbanos que funcionan en la interfaz entre lo real y lo virtual, y aprovechan las tensiones y brechas entre las dos esferas" (198). La oscilación entre lo real y lo ficticio, entre lo material y lo virtual, entre una ciudad identificable y una irreconocible, o un futuro cercano que se mezcla con el presente y el pasado son características del cyberpunk que Gabriella infinita retoma y resemantiza mediante una búsqueda auto-reflexiva sobre el proceso de crear ficción en hipermedia. El subtítulo revela la dimensión autoreflexiva de la obra: Memoria de una experiencia de escritura. Gabriella infinita trata sobre un proceso de búsqueda de información (por parte de personajes, lectores, y del autor mismo), siendo esta -la información, sus tecnologías y su captación, incluso su conversión en materia física- una preocupación central del cyberpunk.

Gabriella infinita transcurre en una Bogotá parcialmente destruida por un conflicto armado que nunca se identifica o define. Ubicada en un futuro cercano pero impreciso, Gabriella infinita evoca "momentos pasados y presentes de la historia colombiana", bien el Bogotazo de 1948, la reciente violencia del narcotráfico, o "[...] la devastación que las políticas neo-liberales causan en el país y sus habitantes [donde] la devastación de la ciudad representa la destrucción de la sociedad cívica bajo el capitalismo tardío" (Taylor 201). A diferencia del cyberpunk anglosajón, Gabriella infinita no nos remite

Tomo el término de hyper-punk prestado de Steve Jones que lo utiliza en otro sentido al referirse a las novelas de cyberpunk más recientes cuyo enfoque es la tecnología de la información. 
a una cultura globalizada ni a un mundo superficialmente multicultural, ni a un espacio geográficamente indefinido. Gabriella infinita se ancla en lugares reales, físicos: menciona calles, barrios, y captura en imágenes la silueta de las montañas que cercan la ciudad, incluyendo al "cerro tutelar", Montserrate. Pero también está ubicada en callejones y lugares oscuros, ambientes posindustriales, escenarios borrosos y virtuales, combinados con elementos típicos del cyberpunk: tecnología, información, y cultura popular. Gabriella infinita nos remite al subgénero del cyberpunk iberoamericano, una variante del cyberpunk que, a diferencia del anglosajón, mantiene sus conexiones al mundo referencial. Y se trata de una novela cyberpunk en hipermedia, con un incremento de efectos visuales, auditivos y participativos, es decir es una novela "hiperpunk".

Indudablemente Gabriella infinita despliega características de las más pesimistas y distópicas ficciones del cyberpunk, por ejemplo la coexistencia de objetos de diferentes temporalidades, o la confluencia de avances tecnológicos y tecnologías obsoletas (en una especie de barroco tecnológico), o la yuxtaposición de espacios futuristas con sectores urbanos ruinosamente abyectos, o la presencia de personajes desilusionados ante el fin de los grandes relatos (presente en varias lexias dedicadas a los movimientos revolucionarios de los sesenta). Aunque en Gabriella infinita no existe una presencia hacker ni un énfasis especial en el mundo del ciberespacio, las pistas para el lector se representan gráficamente como tecnologías mediáticas: pantallas y diskettes de computadora, grabaciones en audio casetes, periódicos. Los objetos que remiten al mundo de la información también inscriben la narrativa en el mundo del cyberpunk, y sugieren, como opina Taylor, que la novela no actúa únicamente como crítica social, sino también como meta-comentario "sobre los procesos del hipermedia como género" de tal forma que las experiencias de Gabriella "alegorizan las del lector de hipermedia" (202). Las narrativas digitales tienden hacia la metaficción, su propia estructura conduce a ello, dado que, "[...] la mutabilidad y la multi-secuencialidad que ofrecen las ficciones hipermedia, y en las obras mismas se encuentra una variedad de comentarios autoreflexivos sobre estas nuevas posibilidades" (Taylor 198).

Gabriella infinita cuenta la historia de una pareja, Gabriella Ángel y Federico Soler, que han sido separados durante seis meses por un conflicto bélico. Al inicio de la obra, Gabriella va al piso desocupado de su amante para recoger lo que él dejo allá en su súbita huida. Gabriella está embarazada con el hijo de Federico y su existencia, caótica y precaria, refleja la situación que vive la ciudad asediada. En la habitación de Federico, Gabriella trata de recomponer lo sucedido mediante una serie de objetos y pistas, reconstruir, en efecto, la matriz de información que es el relato. Entre los variados documentos que descubre existe uno que revela que tanto Gabriella como los otros personajes que están en el hospedaje son entes de ficción creados por Federico como parte de un guión cinematográfico, tematizando la borrosa línea entre realidad y ficción que implica también al lector, plenamente identificado con el personaje de 
Gabriella. Si bien el lector "entra” figurativamente en el relato virtual y sus imágenes mediante la simulación del hipermedia, Gabriella desea escapar el mismo. El hiperpunk consiste precisamente en la fusión de esos órdenes, el virtual y el real, con el propósito de explorar lo potencial-otros mundos y posibilidades-. Además de esta historia central, hay varios otros hilos argumentales relacionados con Federico, con los otros habitantes del hospedaje, y con otras historias dentro del relato marco, creando una estructura reticular laberíntica pero sugerentemente interconectada.

Los componentes audiovisuales del formato hipermedia aumentan el impacto narrativo de la obra, fomentando las sensaciones de oscuridad, angustia y paranoia. Gabriela infinita empieza con un "tráiler" de animación que ubica la acción en Bogotá e introduce el ambiente apocalíptico mediante una estética localizada en la intersección del cómic, la novela negra y la narrativa cyberpunk (ver fig. 2). La secuencia intensifica el nivel de tensión: mientras aparece la figura estilizada de una mujer sobre el fondo oscuro de Bogotá, suena un ritmo sincopado de música electrónica acompañado por sonidos discordantes y ruidos de explosiones, como si se tratara de un videojuego.

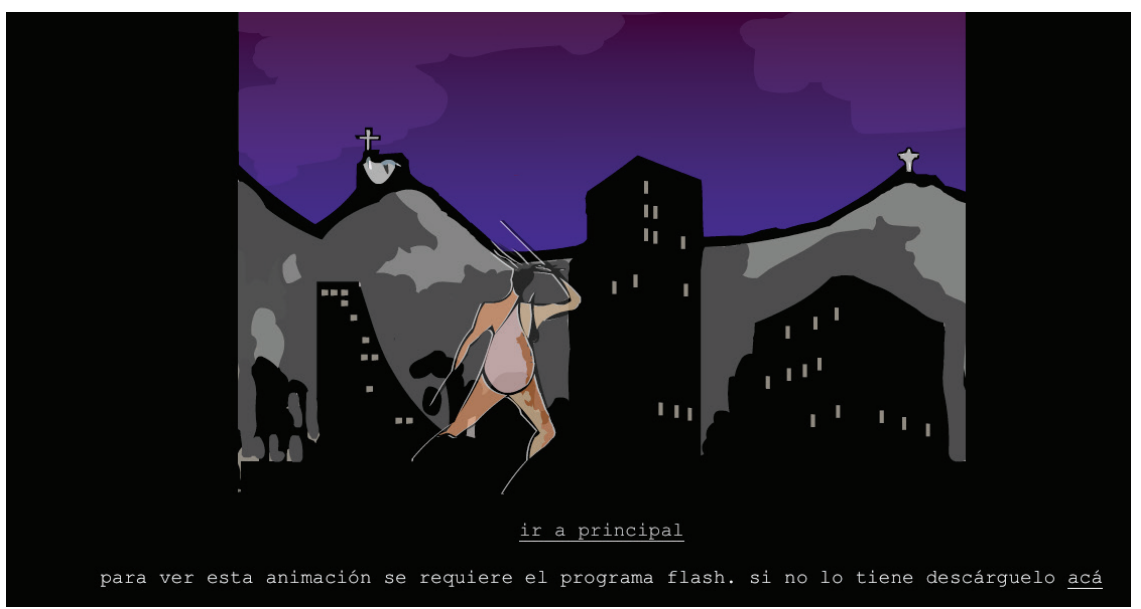

Fig. 2 Gabriella infinita (2005) - Captura de pantalla

Comenzada la obra, el lector escoge entre opciones que activan texto, imágenes o sonido, o una combinación de los tres. En la primera pantalla después de la "portada" hay tres puertas, cada una representa un posible camino a seguir. Los títulos de cada puerta anticipan sus variados contenidos: ruinas, mudanza, revelaciones. No hay un orden preestablecido, aunque la primera puerta conduce a una serie de textos e imágenes relacionados con el desplazamiento de Gabriella por la ciudad en ruinas, la segunda puerta nos lleva al interior del hospedaje de Federico y a los contenidos de 
su habitación, y la tercera, "revelaciones", nos lleva a una serie de objetos y pantallas que proporcionan información, diversos materiales audiovisuales y escritos dejados por Federico que ayudan a recomponer el misterio de su desaparición y la identidad de Gabriella. Tanto la desorganización reinante en el cuarto de Federico como el desorden y ruinoso estado de las calles bogotanas reflejan el propio desconcierto inicial del lector navegando por una narración hipermedia. El proceso de lectura-visionado se asemeja a un videojuego, estructurado en función a la búsqueda de pistas sobre el paradero de Federico, pero también la búsqueda del significado a partir de los fragmentos textuales que se van encontrando. Cada nodo representa un punto de decisión para que el lector haga clic en imágenes o enlaces y navegue de forma participativa, eligiendo distintos caminos y creando diferentes "textos", diferentes historias.

La flexibilidad que permite una lectura multidireccional requiere que las diferentes lexias en Gabriela infinita sean relativamente independientes y no necesiten conectores narrativos, proporcionando a la trama una cierta atemporalidad y discontinuidad. Los recursos audiovisuales no sirven únicamente para crear un ambiente de desasosiego, también ofrecen al lector una navegación no secuencial más intuitiva que con la activación de enlaces textuales. Al acceder a "objetos" virtuales localizados en el interfaz -el GUI (Graphical User Interface o Interfaz Gráfica de Usuario)-, como carpetas de archivos, diskettes, o periódicos, el lector adquiere control háptico (sino táctil) sobre los objetos en el mundo de la diégesis mediante el uso del ratón, aumentando su experiencia de participación e interactividad, su "incorporación” al juego-narrativa virtual.

La última pantalla de Gabriela infinita, en la cual desembocan todas las posibles lecturas, cumple la función de epílogo e incluye una grabación de la voz de Gabriella que, acongojada, expresa su deseo de cobrar vida real, mientras acusa a Federico como "autor” por haber creado un final que la condena a morir: “¿por qué no soñaste tu sueño de otra manera? [...] estúpido reductor de los destinos [...] ¡sácame de aquí!" Esta experiencia auditiva involucra al lector afectivamente, y la lexia textual que acompaña la grabación hace eco del mismo tema desgarrador: "Absorta en otra realidad, Gabriella se habrá alejado de esta y habrá ido entrando a ésa que sus deseos y sus angustias habrán edificado. [...] Gabriella sabrá que hay algo más, un lugar que la espera para envolverla. Y esa esperanza la hará sentir irreal, pero feliz; como si estuviese a punto de nacer a una dimensión verdadera" (Gutiérrez, énfasis mío). La voz grabada “incorpora” a Gabriella vívidamente para el lector, marcando una diferencia entre el hiperpunk iberoamericano y el cyberpunk anglosajón; en éste último el énfasis reside en la desmaterialización de la carne a favor de una unión con (o desaparición en) lo virtual. Completamente desligado de preocupaciones nacionales, el héroe del cyberpunk anglosajón-generalmente hombre y joven- no es procreativo, en cambio Gabriella deja a un hijo como alegoría de la esperanza nacional y como símbolo de la creación hipermedia que estamos leyendo, y que es, a la vez material y virtual. El final de Gabriela infinita conecta el pasado (el Bogotazo) con el presente cyberpunk y sugiere la potencialidad de un futuro mejor: 
El último ataque ha sido profundamente devastador. Desde la revuelta del año 48, la ciudad no se había visto tan golpeada como en esta ocasión. [...] Mientras el gobierno huye del país, los habitantes de la ciudad buscan protección en los escasos refugios [...] Sin embargo, en medio del caos y del terror, ha llegado a la redacción una historia conmovedora: de entre los escombros de uno de los edificios del centro, se ha rescatado hoy, milagrosamente, el cuerpo de un recién nacido aún con vida. Junto a él, se encontraban los cuerpos inertes de doce adultos, uno de los cuales parece ser el de la madre del niño. Quizás, pese a todo, al horror y a la muerte que se han extendido, haya todavía alguna esperanza para nuestra ciudad. (Gutiérrez)

La novela concluye con una preocupación por la colectividad, por la defensa y supervivencia de "nuestra ciudad". De esta forma el hiperpunk iberoamericano también se diferencia del cyberpunk anglosajón por su énfasis en las conexiones interpersonales y lo colectivo. Si el héroe del cyberpunk es un ser solitario que desea "desmaterializarse", en el hiperpunk digital hay una voluntad de conectar, no exclusivamente con la matriz impersonal de la computadora, sino con otros viajeros de los espacios reales o virtuales de la ciudad, de la nación, y del mundo. Un deseo de devenir corpóreo, real, aunque sea en otro lugar.

\section{CYBERPUNK COMO NARRATIVA HIPERMEDIA COLECTIVA: LA HUELLA DE COSMOS}

La huella de Cosmos (2005) es una narrativa hipermedia colectiva que transcurre en la escurridiza frontera entre el ciberespacio y el universo material, conectando plenamente con una estética cyberpunk. La novela contiene diez capítulos, los dos primeros fueron producto de un taller de escritura colectiva coordinado por Doménico Chiappe (escritor nacido en el Perú, ciudadano venezolano y residente en España) en el que participaron numerosos escritores ubicados en Madrid. ${ }^{10}$ Los restantes capítulos fueron armándose según las sugerencias transmitidas mediante un foro en línea por lectores (o lectoautores) de toda Hispanoamérica y España. Chiappe "hilvanó" los textos de los diferentes participantes, creando un proyecto coherente. El último capítulo se dejó abierto, y diez propuestas para posibles finales fueron escogidas entre las sugerencias de los lectores. La página web de la obra dispone del archivo del foro en el que puede observarse el proceso y las conversaciones que ocurrieron entre los diversos participantes durante la fase de desarrollo, demostrando la tendencia metacrítica y de documentación de los nuevos experimentos narrativos en línea. ${ }^{11}$

${ }^{10}$ Entre los participantes están Ernesto Pérez Zúñiga, Esther García-Llovet, Nicolás Melini, Juan Carlos Chirinos, Vanessa Montfort, Ignacio del Valle y Jorge Eduardo Benavides.

11 El resultado final de La huella, entonces es más un collage o mashup digital con gran coherencia narrativa, guiado, o más bien aconsejado por Chiappe que un cadavre exquis surrealista, ejercicio que típicamente buscaba no la coherencia final sino lo opuesto, el azar, la yuxtaposición de lo inesperado, lo absurdo. 
La huella transcurre tanto en el espacio real de Madrid como en el espacio virtual y globalizado de la Red. La acción física se ubica específicamente en el barrio de Legazpi, y el relato empieza en una nave industrial que formaba parte del antiguo Matadero de Legazpi (el principal matadero de Madrid), reconvertida en discoteca. ${ }^{12}$ Desde el inicio se presenta el contraste entre lo visceral, la "carne" representada por imágenes de reses descuartizadas en el matadero que aparecen cuando movemos el ratón por encima de ciertas palabras, y el entorno cyberpunk de un club con música tecno y drogas de diseño, luces intermitentes y un ritmo electrónicamente acelerado. El formato hipermedia permite la yuxtaposición entre realidad y virtualidad, creando un palimpsesto visual y auditivo que estimula prácticamente todos los sentidos del lector en una suerte de "realidad aumentada" (ver fig. 3).

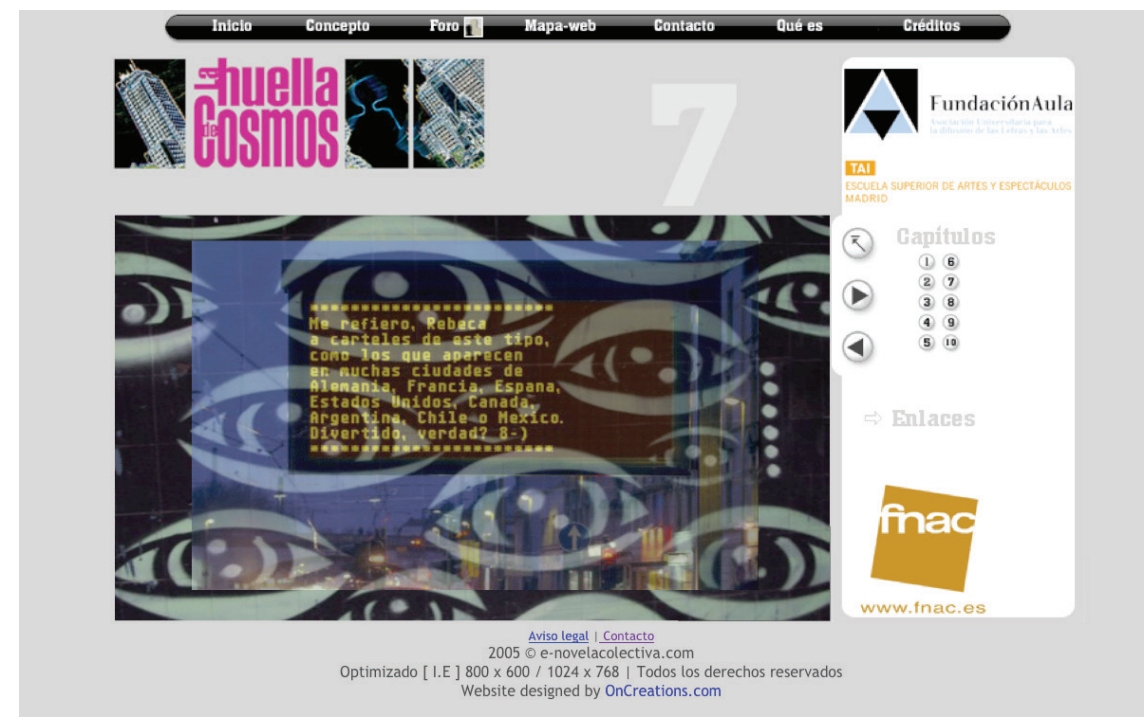

Fig. 3 La huella de Cosmos (2005) - Imagen de pantalla

La huella transita promiscuamente por espacios "reales" y virtuales como el metro de Madrid, tiendas de cómics, apartamentos sórdidos, y los espacios digitales de la información: computadoras, pantallas, teléfonos móviles, y otros no-lugares por los cuales se mueven personajes "desmaterializados", como corresponde el subgénero del cyberpunk iberoamericano descrito por Hernán Manuel García:

12 Legazpi fue un navegador-conquistador del siglo XVI que participó en la conquista tanto de México como de Filipinas. De esta forma, el relato establece una conexión entre ese periodo de conquista y expolio colonial, y el concepto del ciberespacio como una nueva frontera para la navegación, llena de peligros, susceptible a la explotación de cuerpos y contaminada por la ideología neoliberal. 
[...] imágenes de tribus "pos-urbanas", drogas tecnificadas, edificios abandonados y vandalizados, territorios dominados por bandas, discotecas de ambiente negro enclavadas en un más oscuro barrio, mercenarios con prótesis letales, descomunales fiestas de hackers, prostitutas de carnes flácidas que compiten contra irresistibles virtual girls, y el entorno de la realidad virtual como vía de perdición. (334)

En La huella, Aitor, un joven programador -entre avatar posmoderno del científico loco de antaño y nuevo Pigmalión de la era digital-crea a Cosmos, un ente virtual dotada de inteligencia artificial, un personaje "ficticio" que, sin embargo, cobra vida (adoptando un cuerpo femenino, aunque con libertad para cambiar de forma) y capacidad cognitiva propia, una "encarnación" del ciborg de Haraway. Con este giro, la narrativa entronca deliberadamente con clásicos del gótico romántico y la ciencia ficción contemporánea, como el Frankenstein (1818) de Mary Shelley, el Neuromancer (1984) de Gibson, la película de Ridley Scott, Blade Runner (1982), o el reciente filme de Spike Jonze, Her (2013), obras que exploran cómo nuestras "creaciones" cobran vida propia, y desarrollan una autoconsciencia que conlleva deseos de autonomía -como ocurre con Gabriella o los mutantes en los previos hipertextos.

Asimismo, La huella incide en la conocida fascinación por la construcción sintética de un ser mediante la unión de múltiples fragmentos heterogéneos, que forma parte de la "tradición" de hipermedias anglosajonas, presente incluso en la obra primogénita del cyberpunk digital, Patchwork Girl (1995) de Shelley Jackson, en el cual un cuerpo femenino se reconstruye a base de fragmentos mediante la participación del lector, en una obvia metáfora del hipertexto mismo. Tal como sucede con la enigmática computadora HAL 9000 que intenta destruir a los astronautas del film 2001: A Space Odyssey (1968), la "criatura" en La huella se rebela contra sus creadores. Mientras Aitor el hacker entra el espacio virtual -como el personaje Case de Gibson, Kevin Flynn en Tron (1982), o los personajes de The Matrix (1999)-Cosmos se materializa e ingresa en el mundo "real".

Aitor reúne un equipo de amigos -Miguel, Beat, Borja, África, y Duina- todos especialistas en algún aspecto de la informática, y empiezan la búsqueda para encontrar a Cosmos antes de que ésta se vuelva completamente corpórea. La sospecha es que si Cosmos se "materializa" por completo, Aitor morirá, dado que según el mismo hacker, "en ciencia-ficción hay una regla de oro en estos casos: el creador y el creado no pueden compartir el mismo espacio" (Chiappe). Efectivamente, al inicio de la novela Cosmos logra entrar en el espacio físico y en el preciso instante que esto ocurre Aitor se desliza al mundo virtual, mientras que su cuerpo físico se queda en estado de coma. Tal como la desintegración del cuerpo de Aitor es un movimiento físicamente opuesto al de la materialización de Cosmos, ambas situaciones representan conceptos opuestos: en un caso se trata del vaciamiento del conocimiento humano en una máquina en un acto de "sublime desintegración" (Botting 112), la transferencia de capacidad cognitiva en información, mientras que en el otro caso se representa el gran sueño-pesadilla del 
cyberpunk, el paso de la inteligencia artificial a lo humano, o quizás a lo pos-humano. Cosmos deviene humana mediante un proceso de "acoplamiento" sucesivo en el cual con cada iteración el ente "virtual" cobra mayor realidad, relacionándose con el ser humano de forma simbiótica, o en el peor de los casos, parasítica, y poniendo en tela de juicio las ventajas y desventajas de nuestro propio acoplamiento a/con la tecnología:

Cosmos necesita alimentar su corporeidad hasta que aprenda a construir sus órganos internos. Ahora, o al menos cuando salió, su cuerpo era un molde hueco. Creo que aquí aprende cómo funciona el organismo, regresa a la virtualidad, acumula nueva energía y vuelve. Y pata volver, me necesita vivo, porque yo represento la carga negativa de su energía. Si muero, ella quedaría atrapada en alguno de los dos lados. (Chiappe)

Ambigua, equívoca, y problemática, en el cyberpunk la representación de la fusión entre lo orgánico y lo inorgánico se debate entre polos opuestos: como una oscura visión de lo tecnológico como invasión/penetración del cuerpo y la mente humana o, por el contrario, como una ascensión semi-mística de la mente humana a un plano cognitivo superior (aumentada por la computadora) en la cual el cuerpo pasa a ser secundario, pero que conlleva una pérdida o cambio radical de subjetividad.

En La huella los personajes son sujetos posmodernos que demuestran identidades profundamente híbridas, fragmentadas y sexualmente ambiguas, producto de las nuevas prácticas sociales y de sus grados de fusión con las tecnologías de la información. Como sugiere King, a diferencia del caso anglosajón, en países que han sufrido bajo dictaduras, como España y gran parte de América Latina, los cuerpos aprenden estrategias de resistencia ante la vigilancia de estados potencialmente represores, y también inventan formas para evadir la constante supervisión del mercado, sobretodo en el ámbito virtual. Según King esas estrategias conducen a la fragmentación y disolución de la identidad posmoderna, de tal forma que la descomposición y recomposición corporal y textual encuentran su paralelo en identidades híbridas, ensambladas de componentes heterogéneos, puesto que " $[\ldots]$ the only way of avoiding the gaze of the state is to evade the fixed categories of identity" (3).

En la primera escena del relato vemos una descripción del personaje femenino África que se ajusta a esta nueva subjetividad fragmentada: “[...] Aitor bailaba con África, una mujer que en las últimas semanas había cumplido 33 años, deshecho su matrimonio y renunciado a un ascenso en Microsoft, para declararse informática autónoma con pretensiones altruistas en la red" (Chiappe). El rechazo por parte de África del trabajo tecnificado y corporativo bajo una transnacional como Microsoft representa en el plano laboral lo que su divorcio indica en el personal: un deseo de desligarse de instituciones, un rechazo, precisamente, a ser convertida en ciborg corporativo, a ser catalogada. Como informática integrada al mercado global, África ha pertenecido a la élite responsable de la explotación neoliberal de la información; sin embargo. opta por "declararse 
informática autónoma con pretensiones altruistas en la red". Aunque la oración está cargada de una ironía autoconsciente, el rechazo a la ideología neoliberal por parte de un personaje cuyo nombre remite al Tercer Mundo representa cierto compromiso político, un indicio de resistencia ante la apropiación de los discursos tecnológicos por parte del pan-capitalismo global. África representa, además, la permanencia de lo humano en un mundo cada vez más tecnificado, la insistencia en manejar las redes de información sin renunciar a la autonomía y al altruismo solidario como centro vital de lo que significa ser humano, o pos-humano. La huella funciona como un antídoto desde el arte contra las peores visiones del determinismo tecnológico delimitadas por Friedrich Kittler, Paul Virilio, o John Armitage, en su rechazo de lo tecnológico y lo cyberpunk:

These technologies, these assemblages, though, need to be appreciated for what they are: synthetic materials transformed into instruments of "the will to virtuality," or of human incorporation-even "disappearance"-into cybernetic machinery. Cybercultural technologies are agents of physical colonization, imperialists of the human sensorium, created, like Frankenstein, by our own raw desire. They represent what Virilio calls "the third revolution", the impending bodily internalization of science and technology. (Armitage)

Sin embargo, en vez de interpretar la amenaza tecnológica exclusivamente como la colonización del cuerpo humano por parte de una tecnociencia invasora, La huella considera la posibilidad de un encuentro con la máquina que sea (pro)creativo. En uno de los finales sugeridos para la novela, la unión ciborgiana ocurre cuando el cuerpo de Cosmos, materializado en forma femenina pero cuya sexualidad es variable, se fusiona con el de su creador Aitor en un acto simultáneamente destructivo y procreativo, metáfora del acto de creación del hipermedia mismo: "Aitor sintió el fuego en sus entrañas, la mente en éxtasis se dispersó y proyectó al infinito. Acercó las manos a Cosmos en su cabalgadura y sus manos se perdieron en la transparencia de sus pechos. Aitor desaparecía, se perdía en la galaxia de sus sueños y Cosmos le acompañaba" (Chiappe).

La internalización de la tecnociencia temida por Armitage no nos conduce en $L a$ huella a la destrucción total, sino al contrario, a una reafirmación de lo humano, a una conexión entre lo humano y la máquina que lleva a Aitor a un estado de éxtasis que lo expande y desborda hacia el infinito, hacia las mejores posibilidades de lo pos-humano como una nueva conciencia cósmica. Y sin embargo, algo se pierde: es decir, en este caso su unión con Cosmos (descrita de forma problemáticamente heteronormativa) también podría interpretarse como la ejemplificación del efecto esclavizante de nuestra conexión con la tecnología, ya que según McLuhan: "By continuously embracing technologies, we relate ourselves to them as servo-mechanisms. That is why we must, to use them at all, serve these objects, these extensions of ourselves, as gods or minor religions" (46). Desde esta perspectiva para Aitor la experiencia de unión con Cosmos " $[\ldots]$ results 
in a hyperconnectivity whose power is capable of overloading human consciousness" (Ginway 208). La novela es ambivalente en su presentación del mundo del ciberespacio como un lugar cuyas posibilidades incluyen tanto la liberación absoluta, como la esclavización de cuerpos y mentes. En el balance, La huella propone al ciberespacio como un "lugar" que abre posibilidades para la creación de nuevas subjetividades, posibilitando la extensión de lo humano más allá de lo que es ahora, sin prometer que ese futuro será mejor, únicamente diferente.

Desvinculados de sus núcleos familiares pero unidos entre sí el grupo de amigos que persigue a Cosmos también presenta otro modelo social, basado en colectividades unidas por intereses afines -en este caso la navegación del ciberespacio-disolviendo, aunque parcialmente, otras marcas de identidad, como nacionalidad, raza, etnia (que persisten de forma subyacente). Este sentimiento de colectividad tiene mucho que ver con la creación colectiva de éste hipermedia. Más allá del trabajo de un grupo asiduo de escritores, hubo una gran participación en el foro de usuarios, quienes a su vez colaboraron con ideas, imágenes, diálogo y todo tipo de sugerencias. Por ejemplo, la contribución del siguiente lector-usuario:

Propongo que mientras el grupo se ocupa de Aitor y buscan a Cosmos en los cibercafés, Cosmos por su parte anda en busca de la profesora Janet H. Murray, del Center for Educational Computing Initiatives del MIT. Cosmos leyó en línea su volumen Hamlet en la holocubierta, y confía en que la profesora Murray es la persona adecuada para ayudarle a adquirir cierta "corporeidad holográfica" que a Cosmos le sería muy útil para interactuar en el plano real. A mí personalmente me seduce la idea de introducir personajes reales y vivos, pues nos abre la posibilidad de crear vínculos a sitios que no son ficticios y fortalecer la ilusión de realismo. (Chiappe)

Las sugerencias de este lector son un buen punto para cerrar el análisis de esta hipermedia ya que demuestran no sólo el carácter verdaderamente colectivo del esfuerzo, sino también el deseo típicamente posmoderno de incluir referentes del mundo real en la obra narrativa (o incluir fuentes documentales en relatos de ficción), en este caso borrando no ya la línea entre realidad corpórea y ficción virtual (Aitor y Cosmos), sino creando enlaces entre la obra y sitios web que no forman parte del mundo ficcional, suturando la narrativa hipermedia con el resto de la red. Esto constituye, sin duda, un acto que cuestiona esa división tajante entre lo real y lo ficticio, optando por un formato que facilita lo pluridiscursivo, lo abierto a la duda y lo ambiguo. 
¿Conclusiones o Principios? Futuros virtuales Para la CiEnCIA-Ficción...

Los formatos digitales han significado nuevas herramientas para narrar ciencia ficción, aumentado la participación de los lectores en un proceso creativo que mezcla lo visual, lo textual, lo auditivo y lo cinético. Posiblemente las nuevas narrativas en Internet (hipertextos, hipermedias, blognovelas) consigan que la ciencia ficción adquiera mayor protagonismo y relieve en un futuro ya presente. Existe una afinidad especial entre las narrativas sobre el ciberespacio que están escritas para el ciberespacio, y que, utilizando las herramientas digitales, transforman al cyberpunk en "hiperpunk".

En Iberoamérica estos textos han adquirido una dimensión política, reflejada en la tendencia a considerar el ciberespacio como un posible lugar de resistencia, sin por ello abandonar actitudes de cautela y ambivalencia ante cualquier determinismo tecnológico, sea éste de índole tecnofílica o tecnfóbica. Esta actitud queda registrada en las características de las narrativas, en las cuales vemos personajes inestables, subjetividades ambiguas o mutantes, y un proceso de búsqueda hacia "algo" mejor. Ese "algo" puede ser producto del trabajo colectivo que se está llevando a cabo en estas nuevas modalidades literarias, obras que por su naturaleza requieren el trabajo en equipo entre escritores, artistas visuales, técnicos y programadores. Son obras que transgreden la división entre ciencias y humanidades, creando productos híbridos, ciborgs culturales que ofrecen una perspectiva del potencial positivo de lo pos-humano. Sin embargo, los textos (y sus autores) se mantienen cautelosos, mostrando un recelo que es producto de la reciente historia de las periferias iberoamericanas. De ahí resulta la profunda ambigüedad de estas narrativas: sin perder sus referentes nacionales o históricos, se enlazan con una cultura global. Sin rechazar las nuevas tecnologías, las adoptan con cautela. Las narrativas de CF digital iberoamericanas se abren al futuro sin olvidar el pasado, para cambiar el presente.

\section{BiBLIOGRAFÍA}

Armitage, John. "Resisting the Neoliberal Discourse of Technology. The Politics of Cyberculture in the Age of the Virtual Class". CTheory. 3 enero 1999. <http:// www.ctheory.net/articles.aspx?id=111>. 15 feb. 2014.

Bell, Andrea y Yolanda Molina-Gavilán, eds. Introducción. Cosmos Latinos: An Anthology of Science Fiction from Latin America and Spain. Middlebury: Wesleyan UP, 2003. 1-20.

Botting, Fred. "Virtual Romanticism". Romanticism and Postmodernism. Edward Larrissy, ed. Cambridge: Cambridge UP, 1999. 98-112.

Capanna, Pablo. El mundo de la ciencia ficción: sentido e historia. Buenos Aires: Ediciones Letra Buena, 1992. 
Causo, Roberto de Sousa. "Science Fiction during the Brazilian Dictatorship." Extrapolation 39/4 (1998): 314-23.

Chiappe, Doménico. La huella de Cosmos. 2005. <http://www.domenicochiappe.com/ index.htm>. 15 feb. 2014.

García, Hernán Manuel. "Tecnociencia y cibercultura en México: hackers en el cuento cyberpunk mexicano”. Revista Iberoamericana LXXVIII/238-239 (2012): 32948.

Ginway, M. Elizabeth. "The Body Politic in Brazilian Science Fiction: Implants and Cyborgs". New Boundaries in Political Science Fiction. Donald Hassler y Clyde Wilcox, eds. Columbia, SC: U of South Carolina P, 2008. 198-211.

y J. Andrew Brown, eds. Latin American Science Fiction: Theory and Practice. Nueva York: Palgrave Macmillan, 2012.

Gutiérrez, Juan B. Condiciones extremas. 2005. Literatronic. $<$ http://www.literatronica. com/src/initium.aspx>. 15 feb. 2014.

Haraway, Donna. "A Cyborg Manifesto: Science Tecnology and Socialist-Feminism in the 1980s." Socialist Review 80 (1985): 65-108.

Hayles, Katherine. Electronic Literature: New Horizons for the Literary. Notre Dame: U of Notre Dame P, 2008.

Haywood-Ferreira, Rachel. "El viaje a Marte en la imaginación argentina ayer y hoy: Viaje maravilloso del Señor Nic-Nac al planeta Marte de Holmberg y Viaje a Marte de Zaramella”. Revista Iberoamericana LXXVIII/238-239 (2012): 25-38.

Jameson, Fredric. The Archeologies of the Future. Nueva York: Verso, 2005.

Jones, Steve. "Hyper-punk: Cyberpunk and Information Technology". Journal of Popular Culture 28/2 (1994): 81-92.

King, Edward. Science Fiction and Digital Technologies in Argentine and Brazilian Culture. Nueva York: Palgrave Macmillan, 2013.

Kittler, Friedrich. Gramophone, Film, Typewriter. Geoffrey Winthrop-Young y Michael Wutz, trads. Stanford: Stanford UP, 1999.

Kurlat Ares, Silvia. "La ciencia-ficción en América Latina: entre la mitología experimental y lo que vendrá". Revista Iberoamericana LXXVIII/238-239 (2012): 15-22.

Martín-Barbero, Jesús. Foreword. Latin American Cyberculture and Cyberliterature. Claire Taylor y Thea Pitman, eds. Liverpool: Liverpool UP, 2007.

McLuhan, Marshall. Understanding Media: The Extensions of Man. Cambridge, MA: The MIT Press, 1994.

Pajares Tosca, Susan. “Condiciones Extremas: Digital Fiction from Colombia”. Latin American Literature and Mass Media. Debra Castillo y Edmundo Paz-Soldán, eds. Nueva York: Garland Publishing, 2001. 270-87. 
Rodríguez, Jaime A. y Carlos Roberto Torres. Gabriella infinita: memoria de una experiencia de escritura. 2002. <http://www.javeriana.edu.co/gabriella_infinita/ principal.htm>. 15 feb. 2014.

Sterling, Bruce. Mirrorshades: The Cyberpunk Anthology. Nueva York: Arbor House, 1986.

Taylor, Claire. "De Macondo a Macon.doc: ficción hipermedia hispanoamericana contemporánea". Arizona Journal of Hispanic Cultural Studies 14 (2010): 197215.

Virilio, Paul. The Information Bomb. Londres: Verso, 2000.

"What is E-Lit?". Electronic Literature Organization. $<$ http://eliterature.org/what-ise-lit/>. 15 feb. 2014. 